\title{
A ESCOLA E O SEU PAPEL NA CONSTRUÇÃO DO PROTAGONISMO JUVENILE
}

\section{ARTIGO DE REVISÃO}

SÁ, Robison Gomes de ${ }^{1}$

SÁ, Robson Gomes de. A escola e o seu papel na construção do protagonismo juvenil. Revista Científica Multidisciplinar Núcleo do Conhecimento. Ano 04, Ed. 08, Vol. 03, pp. 74-83. Agosto de 2019. ISSN: 2448-0959

\section{RESUMO}

Neste trabalho, pretende-se refletir sobre a importância da escola no desenvolvimento do Protagonismo, buscando estabelecer conexões entre as características do protagonista com a realização dos seus Projetos de Vida. Aqui, ainda será indicada a criação de espaços para a vivência do protagonismo no dia a dia escolar, objetivando compreender o jovem como fonte de iniciativa, liberdade e compromisso, numa escola que busca formar cidadãos autônomos, competentes e solidários.

Palavras-chave: protagonismo, escola, espaços de protagonismo.

${ }^{1}$ Especialista em Educação Matemática para Pedagogos. Licenciatura Plena em Matemática. 


\section{INTRODUÇÃO}

A educação, diante dos enormes desafios do nosso século, tem buscado se adequar e oferecer uma formação que não apenas alcance a dimensão cognitiva do aluno, mas também as dimensões do seu corpo, do seu espírito, das suas emoções. Assim, a educação começa a perder a sua unidimensionalidade, passando a ser interdimensional.

Contudo, essa transformação ainda se dá a passos lentos. Porém, mesmo devagar, não se pode negar o fato de que a transformação está acontecendo e, de forma positiva, vem presenteando os jovens com uma formação para a vida, construindo, pouco a pouco, um leque de habilidades necessárias ao enfrentamento dos desafios do século XXI.

Desta forma, a escola começa a descartar ações aleatórias, enquanto prioriza ações intencionais e efetivas.

Sem dúvidas, o processo é complexo e bastante dispendioso, mas os resultados são exponencialmente positivos.

Para que toda essa transformação aconteça, é necessário situar o jovem no cerne dos acontecimentos, sendo ele parte da solução dos problemas, e não o problema em si. É importante envolvê-lo no processo de avaliação e tomada de decisões, fazendo com que ele desenvolva o senso de responsabilidade sobre a própria vida, assumindo a linha de frente das ações que executam, sendo, enfim, protagonistas.

Para que o protagonismo floresça, a escola deve criar espaços adequados ao seu desenvolvimento. Estes espaços são verdadeiros "laboratórios" de protagonismo, nos quais os discentes, diante de situações da vida real, podem fazer suas avaliações e fazer posicionamentos, modificando, assim, a realidade em que vivem.

Dentre os quatro princípios educativos constitutivos do modelo pedagógico da Escola da Escolha - Protagonismo, Quatro Pilares da Educação, Pedagogia da Presença e 
Educação Interdimensional —, iremos nos aprofundar apenas no primeiro, pincelando os demais e deixando a discussão de cada um deles para artigos distintos e futuros.

\section{O QUE É PROTAGONISMO?}

Ao consultarmos o "Dicio", dicionário online da Língua Portuguesa, constatamos que protagonismo é a "qualidade da pessoa que se destaca em qualquer situação, acontecimento, exercendo o papel mais importante dentre os demais [...]."

Antonio Carlos Gomes da Costa (apud ICE, 2016, p. 21), afirma que "protagonismo juvenil é a participação de adolescentes atuando como parte da solução e, não, do problema, no enfrentamento de situações reais, na escola, na comunidade e na vida social mais ampla".

Portanto, ser protagonista é estar em destaque, tomar decisões, ser parte da solução dos problemas.

\section{PROTAGONISMO E PROJETO DE VIDA}

Como centralidade do modelo pedagógico da Escola da Escolha, que contempla o Ensino Médio em Tempo Integral em diversos Estados brasileiros, está o Jovem e o seu Projeto de Vida. O sonho, antes apenas visto como algo inatingível, ganhou corpo, metas, estratégias e ações, amplificando as chances de sua concretização.

Para isso, o jovem é levado à uma profunda reflexão sobre as suas potencialidades, os seus limites, os seus talentos, as suas habilidades e sobre quem ele, de fato, é. Afinal, não se pode dar início a uma viagem sem que se conheça e planeje o percurso.

São os mais variados projetos de vida elencados pelos discentes. Uns, profissões; outros, não. Porém, o que de fato interliga todos eles são a necessidade do compromisso, da tomada de decisões e das consequências que essas decisões, obrigatoriamente, devem trazer. 
Nessa ótica, o desenvolvimento do protagonismo é necessário para o sucesso na realização dos projetos vitais, uma vez que coloca o jovem de frente para problemas reais, envolvendo-os na busca por soluções e, de certa forma, degustando o mundo para o qual eles estão prestes a partir em busca de seus sonhos.

\section{A ESCOLA E OS ESPAÇOS DE PROTAGONISMO}

Espaço privilegiado para a aprendizagem, a escola é, também, ambiente propício para a socialização e inserção de jovens em debates de temas de abrangência geral. $\mathrm{Na}$ modalidade em tempo integral, as possibilidades de movimentar temas geradores de discussões e provocar as possíveis soluções, pelos diferentes grupos de alunos, é ainda maior.

Contudo, antes de prosseguirmos para algumas sugestões de espaços de protagonismo, é necessário lembrar de que toda ação educativa deve ser intencional e, portanto, planejada, executada, avaliada e, se necessário, ajustada. Claro que, se uma boa oportunidade surge do acaso, devemos aproveitá-la, mesmo que ela não tenha sido devidamente planejada. Por outro lado, saltada a etapa do planejamento, podemos prosseguir com as demais etapas do ciclo PDCA (PLAN (planejar) - DO (executar)- CHECK (avaliar) - ADJUST (ajustar)).

\subsection{ACOLHIMENTOS}

Todo dia letivo começa com um acolhimento e todo acolhimento pode ser um espaço para o desenvolvimento do protagonismo.

No tempo breve que se tem para o acolhimento do início do dia, pode-se dar início a uma gigantesca discussão sobre temas como: desigualdade social, direitos da criança e do adolescente, orçamento público, prevenção e combate a doenças virais, acessibilidade, preconceito, bullying, profissões, meio ambiente etc.

Aqui, por meio dos Clubes de Protagonismo, inicialmente com o apoio de um docente ou do gestor escolar, uma agenda de acolhimento poderá ser criada, levando os jovens ao exercício do planejamento, do estudo sobre os mais variados temas, da 
execução do acolhimento, dos ajustes necessários ao planejamento e ao levantamento de propostas de soluções ou aperfeiçoamentos para as problemáticas apresentadas.

Obviamente, o tempo não é suficiente para o aprofundamento dos temas, que poderão ganhar nova discussão em rodas de debates na sala, em seminários temáticos, em grupos de estudo, em pesquisas nas aulas de estudo orientado, em casa etc.

O mais importante aqui é ofertar ao aluno a possibilidade de ele ser ativo, de ele participar desde a concepção da ideia até a sua execução. Aqui, conseguimos enxergar claramente os Quatros Pilares da Educação sendo movimentados e o protagonismo sendo exercitado.

De início, o auxílio do professor é altamente importante. Afinal, os discentes estão experimentando o novo. Porém, com o passar do tempo, as ideias de temas, a elaboração da agenda, a discussão sobre os objetivos e a metodologia a ser adotada, tudo isso e muito mais, será germinado, regado, cuidado e colhido pelos próprios alunos.

Percebemos, portanto, como o acolhimento é um importante espaço para a vivência do protagonismo.

\subsection{ORIENTAÇÃO DE ESTUDO (O.E.)}

A essência do Estudo Orientado (ou Orientação de Estudo) não está propriamente nas aulas, mas em todo um planejamento que as precede. Essa metodologia foi criada para favorecer o autodidatismo e as ferramentas que dele decorrem: planejamento, pesquisa, organização, compromisso, disciplina etc.

A Orientação de Estudo também carece de uma agenda, que é o desaguar de uma correnteza de procedimentos anteriores a ela. Por exemplo, o professor deverá fazer o seu monitoramento de currículo, apontando conteúdos previstos, dados, aprendidos e não aprendidos. No caso dos conteúdos não aprendidos, uma boa estratégia é leválos ao Estudo Orientado. As coordenações de áreas podem colecionar os conteúdos 
não aprendidos e encaminhá-los à coordenação pedagógica, que coleciona todos eles e encaminha-os para os professores de O.E e para os tutores. Os tutores, de posse do material, reúnem-se com os seus tutorados e constroem, juntos, a agenda de cada um, uma vez que nem todos os conteúdos contidos na lista geral é motivo de dúvidas para todos.

Onde entra o protagonismo aqui? Desde o monitoramento. Para saber o que o aluno aprendeu é necessário um diálogo honesto com eles, pois nem sempre uma prova nos dá um diagnóstico da situação real de cada um. Esse diálogo exige uma tomada de consciência sobre a responsabilidade que eles terão sobre suas aprendizagens e o quanto isso será importante para que tenham uma Formação Acadêmica de Excelência, para a Vida e com Competências que eles possam utilizar na resolução dos desafios do nosso Século.

Só nesse fato, o protagonismo já se evidencia. Quando desembocar na tutoria, mais uma vez, ele desabrocha, pois o aluno será responsável pela construção de sua agenda. A agenda apontará os pontos de atenção, aquilo que demandará um foco maior por parte deles. Futuramente, essa agenda será feita de forma autônoma por eles, sendo apenas apresentada ao tutor, e não co construída por ele.

$\mathrm{Na}$ aula de O.E., o aluno deverá seguir o seu planejamento, ser honesto consigo mesmo, manter o compromisso e estar sempre ciente das implicações das negligências em seu Projeto de Vida. Ele deve estar sempre ciente da importância de suas ações para o sucesso de sua vida pessoal, social e produtiva. Isso é protagonismo.

\subsection{PRÁTICAS EXPERIMENTAIS E AULAS DE PROJETO DE VIDA}

As aulas experimentais das ciências são um ótimo espaço para o exercício do Protagonismo. Principalmente quando o professor não desenvolve todos os procedimentos teóricos e práticos, dando as conclusões e embasamentos, sem sequer abrir espaço para a externalização da curiosidade dos jovens. 
Primeiro, é muito importante estimular a curiosidade dos discentes, introduzindo a aula com problemas motivadores. O professor, no protagonismo, deve ser um bom ouvinte, um organizador, um facilitador, um co criador junto aos estudantes. É preciso uma mudança de postura do docente, também. Deve-se lembrar de que a participação dos alunos é a intenção desse processo de construção. De início, a cooperação do professor é muito importante, mas não se deve esquecer de que a autonomia do aluno é o fim.

Portanto, o professor, organizador da aula, guia os alunos, que levantam questões, debatem sobre elas, manipulam os materiais e geram conclusões que, mais tarde, serão correlacionadas com a teoria científica propriamente dita.

O mesmo acontece com as aulas de Projeto de Vida. Se o professor apenas explanar o tema e tirar todas as conclusões, perde-se um espaço rico para a construção do protagonismo. Afinal, as aulas de P.V. são construídas para os alunos. Não que o professor não se modifique ao passar por elas, pois essa mudança é imediata, mas a centralidade da aula é o discente. Assim, quando o problema é proposto, deve-se manter o ouvido atento aos questionamentos dos alunos, às correlações dos exemplos dados pelo professor com as suas vivências. O professor deve observar o visível e o invisível, pois, na grande maioria das vezes, os sentimentos não são externalizados com palavras, mas os sinais corporais denunciam as emoções prestes a explodir.

Podemos dizer, assim, que uma das grandes virtudes do professor que busca o protagonismo autêntico do aluno é enxergar a centralidade deste, uma vez que é para a realização do seu P.V. que toda a escola trabalha. Isso não quer dizer que o professor perdeu a sua importância no processo de educar. Muito pelo contrário. Agora, com um olhar mais atento e espírito solidário, o docente organiza os processos educativos, observa a intencionalidade das ações, co cria com os seus alunos, provoca questões, orienta, está mais presente do que nunca em suas vidas. 


\subsection{AULAS E MOMENTOS AVALIATIVOS}

Diz Moretto (2010, capa) que "A prova deve ser um momento privilegiado de estudo, não um acerto de contas". Sim, a prova deve ser momento de aprendizagem, de reflexão, de questionamentos, de encarar problemas com seriedade e tentar contribuir para as suas soluções. Não estou falando apenas da solução cobrada no instrumento avaliativo, mas, se a prova for bem elaborada, ela deve deixar no aluno um sentimento de querer se aprofundar na temática e, dentro dos seus limites e possibilidades, pensar formas de contribuição para o debate dos temas.

Claro que este tópico não compreende apenas o instrumento avaliativo "prova", mas todos os instrumentos que visam realizar a culminância de todo um processo de ensino e de aprendizagem. Assim, nos seminários, nos debates em grupos, nas rodas de conversas, na autoavaliação, nas aulas práticas, nas aulas de campo e em todos os momentos onde se vivencia a aprendizagem, deve-se provocar e observar o florescimento do protagonismo.

Se expandirmos mais esse pensamento, podemos transformar todas as aulas em verdadeiros espaços de protagonismo. Ora, a gente nem mesmo deveria separar "aulas" e "avaliações", uma vez que todos os momentos exigem algum tipo de avaliação, devendo ser aproveitados ao máximo. Estamos em constante estado de avaliação: avaliação da própria prática, avaliação cognitiva do aluno, avaliação socioemocional, avaliação de uma simples fala, avaliação do sistema de ensino etc. A gente não para de avaliar. Isso é bom, pois os ajustes se iniciam logo após uma criteriosa avaliação.

Por isso, transformar as aulas em espaços de protagonismo potencializa sobremaneira a transformação do aluno em um ser de iniciativas, de liberdade e de compromisso. 


\subsection{PROJETOS ESCOLARES}

Toda escola executa ao longo de todo o ano letivo diversos projetos escolares. Há escolas que até mesmo trabalha apenas com projetos. Eis aqui excelentes espaços de protagonismo.

Anteriormente à culminância dos projetos, há todo um envolvimento dos discentes em sua construção: organizam-se em grupos, elaboram cronogramas, encenam, ensaiam, dançam, desenham, lideram, são liderados, convivem, decidem, pesquisam, executam, avaliam os resultados ao longo do trajeto. Na culminância, todos observam extasiados o resultado dos esforços individuais e coletivos, percebem a importância da tomada de decisões e de se manter ativo quanto a sua aprendizagem, vislumbram o futuro que, nos seus sonhos, já ganhou corpo.

Um projeto escolar nunca aborda apenas um tema. Vários outros temas são levantados e discutidos pelos jovens ao longo do seu desenvolvimento. Muitos problemas surgirão e precisarão ser resolvidos. Muitos conflitos acontecerão e precisarão ser pacificados. Tudo isso contribui, e muito, para que o aluno se compreenda como autor e ator principal de sua própria história.

\subsection{CLUBES DE PROTAGONISMO}

Os Clubes de Protagonismo, como sua própria denominação sugere, é um espaço de autonomia dos discentes, de tomada de decisões, de iniciativas, de convivência e, consequentemente, de mediações de conflitos.

Nos clubes, os jovens organizam as suas atividades, elaboram planos de ação, estabelecem objetivos, executam suas tarefas, promovem eventos, fazem campanhas etc.

Para além de um momento de encontro para um bate-papo despretensioso, dos clubes brotam ações intencionais, fundamentadas e com vieses pedagógicos. 


\section{PROTAGONISMO EM TODO LUGAR}

Até aqui, foram sugeridos diversos momentos escolares propícios às vivências do protagonismo. A escola, neste ponto, passa a ser enxergada como, de fato, uma verdadeira máquina de construção desses espaços. Contudo, não é apenas isso que favorece o protagonismo. Reflitamos um pouco mais sobre a temática.

Desenvolve o protagonismo os alunos que participam de:

\subsection{MOVIMENTOS ESTUDANTIS/SOCIAIS}

Uma vez engajado em causas de interesse coletivo, ele, mesmo que não solucione sozinho o macro problema, se coloca como parte dessa solução. O seu envolvimento o coloca como ser ativo na educação, procurando discutir sobre a saúde do meio ambiente, das finanças públicas, da população, sobre as causas da fome, sobre os problemas da própria educação, entre outros temas relevantes.

As manifestações estudantis são uma forte evidência do destaque do jovem na busca por melhorias coletivas e garantidas pelas leis. Isso ocorre quando, nas ruas ou nas redes sociais, manifestam-se contra os descasos dos governos relacionados à educação, seja no atingimento direto ao professor, seja na falta de estruturas físicas adequadas, condições financeiras escassas para a auto sustentação da escola ou mesmo na falta gritante de recursos pedagógicos para a potencialização do ensino e a facilitação da aprendizagem, bem como quando se manifestam em favor do bem comum sobre as mais diversas problemáticas levantadas.

\subsection{GRUPOS SOCIAIS}

Quando buscam, por meio da força coletiva, fortalecer-se e fortalecer o outro. A sua participação em equipes esportivas, em clubes de leitura, em grupos de solidariedade, grupos religiosos, científicos, entre outros, sejam eles presenciais ou virtuais, leva-o à integração com o mundo amplo, ao qual deverá contribuir com o seu interesse e com 
suas ações. Em todos eles, o discente se constrói, evolui e tona-se capitão do seu próprio navio.

\subsection{TRABALHOS VOLUNTÁRIOS}

Participar de trabalhos voluntários é evolutivo. Além de realizar a atividade, que, na maioria das vezes é de obrigação do Estado, o jovem ameniza a dor do outro, enquanto cobra das autoridades uma solução definitiva do problema.

\subsection{PALESTRAS E DEBATES}

Não são raras as vezes em que os Municípios e Estados ofertam palestras sobre os mais variados temas com participação ativa dos jovens. Nelas, os discentes podem se aprofundar em temas variados - meio ambiente, saúde, direito etc. —, ampliando a sua formação e protagonizando verdadeiros debates acerca desses temas.

\subsection{AUDIÊNCIAS PÚBLICAS E SESSÕES ORDINÁRIAS/EXTRAORDINÁRIAS}

Ao se inteirar sobre finanças públicas, prestações de contas, aprovação e revisão de leis, direitos e garantias, o jovem pode se posicionar diante de fatos de interesse coletivo, aprofundando o seu conhecimento com pesquisas de qualidade e contribuindo para os debates que acontecem nesses momentos tão importantes na tomada de decisões.

\section{CONSIDERAÇÕES FINAIS}

Bem, seria muito pretensioso de minha parte querer elencar num artigo, ou em centenas deles, todas as possibilidades de exercício do protagonismo. A intenção do trabalho, na verdade, é apontar o Norte.

A escola, apesar de não ser o único veículo que conduz ao protagonismo, pode, e deve, explorar a sua potencialidade nessa área. Para isso, é preciso que os educadores — professores, gestores, coordenadores, pessoal de apoio — estejam 
atentos às oportunidades para potencializá-las. Além disso, as ações devem ser intencionais. Para isso, a interação entre os diversos atores da educação deve ser permanente, proporcionando a troca de ideias, intercalando as propostas, enraizando o protagonismo em todos os minutos da atividade escolar. Assim, com um trabalho intenso e proposital, a escola poderá levar o aluno a desenvolver o interesse pelos processos educativos, uma vez que da sua construção ele fará parte, passando à tomada de iniciativas, tonando-se livres para escolher e caminhando lado a lado com o compromisso. Essas três características juntas - iniciativa, liberdade e compromisso - solidificarão a formação de um aluno competente, autônomo e solidário.

\section{REFERÊNCIAS}

Instituto de Corresponsabilidade pela Educação. Modelo Pedagógico: Princípios Educativos, Ed. 2. Pernambuco: ICE, 2016, 60 p.

Nova Escola. Escola é espaço de aprendizagem e protagonismo. Disponível em http://abre.ai/8lb. Aceso em 21 de julho de 2019.

MORETTO, Vasco Pedro. Prova: Um momento privilegiado de estudo, não um acerto de contas, Ed. 9. Rio de Janeiro: Lamparina, 2016, 186 p.

MORIN, Edgar. Os Sete Saberes Necessários à Educação do Futuro, Ed. 2. São Paulo: Cortez Editora, 2011, $102 \mathrm{p}$.

MACHADO, Ana Maria [et. al.] . 5 Atitudes Pela Educação: Orientações para Coordenadores Pedagógicos. São Paulo: Moderna, 2014, 118 p.

SILVA, Zeneide. Todo Educador Deve Saber. Recife: Prazer de Ler, 2017, 112 p.

Enviado: Julho, 2019.

Aprovado: Agosto, 2019. 